\title{
Predicting post-operative pancreatic fistula: one size may not fit all
}

\author{
Mariam F. Eskander, Jordan M. Cloyd \\ Department of Surgery, Division of Surgical Oncology, The Ohio State University Wexner Medical Center; Columbus, OH, USA \\ Correspondence to: Jordan M. Cloyd, MD. Assistant Professor, Department of Surgery, Division of Surgical Oncology, The Ohio State University \\ Wexner, 410 W 10th Ave, N907 Doan Hall, Columbus, OH 43210-1267, USA. Email: Jordan.Cloyd@osumc.edu. \\ Comment on: Kang JS, Park T, Han Y, et al. Clinical validation of scoring systems of postoperative pancreatic fistula after pancreatoduodenectomy: \\ applicability to Eastern cohorts? Hepatobiliary Surg Nutr 2019;8:211-8.
}

Submitted May 19, 2020. Accepted for publication Jun 02, 2020.

doi: 10.21037/hbsn-20-497

View this article at: http://dx.doi.org/10.21037/hbsn-20-497

Post-operative pancreatic fistula (POPF) is a common and dangerous complication of pancreatic resection, occurring in $5-30 \%$ of patients. It is a significant source of morbidity and mortality, leading to prolonged hospital stays and increased healthcare costs (1). The most widely accepted definition of POPF comes from the International Study Group on Pancreatic Fistula (ISGPF). Initially created in 2005, this classification system for POPF was revised in 2016 such that POPF should be associated with a clinically relevant change in status, deeming what was originally defined as a Grade A fistula as a biochemical leak and grade B and C fistulas as clinically relevant (CR) fistulae (Table 1) (2).

Over the past several decades, numerous fistula prediction scores have been developed that attempt to stratify patients according to their risk of developing this potentially morbid complication. Prediction scores can be used to counsel patients pre-operatively, change surgeon behavior in the operating room, direct post-operative evaluation and treatment such as early removal of drains, and potentially minimize adverse events in high-risk patients. The variety of fistula risk scores include pre-operative, intra-operative, and post-operative variables. Examples of some of the most commonly used POPF prediction scores are presented in Table 2. Importantly, many of the risk factors for POPF are non-modifiable, including pancreatic gland texture, diameter of pancreatic duct, diagnosis, age and gender.

The current study by Kang et al. (9) aimed to externally validate three Western POPF prediction models, the Callery model (also known as the Fistula Risk Score) (3), the Roberts model (7), and the Mungroop model (also known as the alternative Fistula Risk Score) (4), in a Korean cohort where patient characteristics, surgical techniques and post-operative practices may differ. Their population consisted of 1,898 patients from nine tertiary hospitals in Korea. Compared to the three western modeling populations, the Korean population had fewer rates of pancreatic ductal adenocarcinoma, lower mean body mass index (BMI), and higher estimated blood loss, though rates of CR-POPF were similar. On multivariate analysis, nonpancreatic disease, higher BMI, and soft pancreatic texture were independent predictors of CR-POPF in the Korean model. The Western scoring systems, which had exhibited reasonable discriminatory ability on previously published internal and external validation studies, performed less well in the Korean cohort, with AUC values ranging between 0.61 and 0.64 .

The findings from Kang et al. are relevant because they suggest that POPF prediction is not necessarily a one size fits all approach. Factors unique to an institution's or geographic region's patient population, disease characteristics, or perioperative practices may influence the incidence of and unique risk factors for POPF development. These findings suggest that, despite the global burden and impact of POPF, unique risk prediction models may need to be developed to accurately capture an individual's risk for CR-POPF following pancreatectomy.

At the same time, predicting POPF is most useful if effective mitigation strategies can be implemented based on risk stratified models. Currently, there are few effective strategies to reduce the occurrence and/or 
Table 1 Definition of POPF as per International Study Group for Pancreatic Surgery (ISGPS), 2016

\begin{tabular}{ll}
\hline Grade & Definition \\
\hline Biochemical Leak & Increased amylase $>3$ times upper limit of normal \\
Grade B POPF & $\begin{array}{l}\text { Requires change in post-operative management; drains either left in place or repositioned endoscopically or } \\
\text { percutaneously }\end{array}$ \\
Grade C POPF & Requires re-operation or leads to organ failure and or death \\
\hline
\end{tabular}

Table 2 Examples of POPF risk prediction scores

\begin{tabular}{|c|c|c|c|c|c|}
\hline Authors & Year & $\begin{array}{l}\text { Modeling } \\
\text { cohort (n) }\end{array}$ & $\begin{array}{l}\text { Outcome of } \\
\text { interest }\end{array}$ & Elements & $\begin{array}{l}\text { AUC on internal } \\
\text { validation }\end{array}$ \\
\hline Callery et al. (3) & 2013 & 233 & Grades B, C & $\begin{array}{l}\text { Gland texture, pathology, pancreatic duct diameter, } \\
\text { intra-operative blood loss }\end{array}$ & 0.94 \\
\hline $\begin{array}{l}\text { Mungroop et al. (Dutch } \\
\text { Pancreatic Cancer Group) (4) }\end{array}$ & 2019 & 1,924 & Grade B, C & Gland texture, pancreatic duct diameter, BMI & 0.75 \\
\hline Yamamoto et al. (6) & 2011 & 279 & Grades B, C & $\begin{array}{l}\text { Sex, pancreatic duct index, relationship of tumor to portal } \\
\text { vein, intra-abdominal fat thickness, pathology }\end{array}$ & 0.81 \\
\hline Roberts et al. (7) & 2014 & 217 & Grades A-C & BMI, pancreatic duct diameter & 0.75 \\
\hline Kantor et al. (8) & 2017 & 1,212 & Grades B, C & Sex, BMI, bilirubin, pancreatic duct diameter, gland texture & 0.70 \\
\hline
\end{tabular}

severity of POPF. For example, the use of perioperative somatostatin analogues remains controversial without convincing evidence of their routine efficacy (10). Preoperative optimization of nutrition is recommended and there is some evidence that neoadjuvant chemotherapy is associated with lower rates of POPF, but these factors will not apply to all patients (11). One multinational retrospective study in patients undergoing distal pancreatectomy found that method of transection, suture ligation of the pancreatic duct, staple size, staple line reinforcement, tissue patches, biologic sealants and prophylactic octreotide were not independently associated with decreased occurrence of CR-POPF (12). Although data on technical strategies to minimize CR-POPF have largely been unsuccessful, some have suggested that the use of externalized stents may reduce the incidence of CRPOPF (13). While the use of routine drain placement after pancreatectomy remains controversial (14), one of the most promising methods of minimizing CR-POPF is early drain removal (15). Clearly, additional research in novel mitigation strategies is needed.

In summary, the study by Kang et al. highlights the global scope of POPF and the need for better prediction models for Eastern populations which may differ from their Western counterparts. Future studies may choose to utilize larger international cohorts and apply innovative machinelearning based techniques to optimize and generalize risk prediction strategies. In the meantime, however, more effective mitigation strategies for POPF are needed to maximize the utility of these scoring systems in clinical practice.

\section{Acknowledgments}

Funding: None.

\section{Footnote}

Provenance and Peer Review: This article was commissioned by the editorial office, Hepatobiliary Surgery and Nutrition. The article did not undergo external peer review.

Conflicts of Interest: Both authors have completed the ICMJE uniform disclosure form (available at https://hbsn. amegroups.com/article/view/10.21037/hbsn-20-497/coif). The authors have no conflicts of interest to declare. 
Ethical Statement: The authors are accountable for all aspects of the work in ensuring that questions related to the accuracy or integrity of any part of the work are appropriately investigated and resolved.

Open Access Statement: This is an Open Access article distributed in accordance with the Creative Commons Attribution-NonCommercial-NoDerivs 4.0 International License (CC BY-NC-ND 4.0), which permits the noncommercial replication and distribution of the article with the strict proviso that no changes or edits are made and the original work is properly cited (including links to both the formal publication through the relevant DOI and the license). See: https://creativecommons.org/licenses/by-nc-nd/4.0/.

\section{References}

1. Vallance AE, Young AL, Macutkiewicz C, et al. Calculating the risk of a pancreatic fistula after a pancreaticoduodenectomy: a systematic review. HPB (Oxford) 2015;17:1040-8.

2. Bassi C, Marchegiani G, Dervenis C, et al. The 2016 update of the International Study Group (ISGPS) definition and grading of postoperative pancreatic fistula: 11 Years After. Surgery 2017;161:584-91.

3. Callery MP, Pratt WB, Kent TS, et al. A prospectively validated clinical risk score accurately predicts pancreatic fistula after pancreatoduodenectomy. J Am Coll Surg 2013;216:1-14.

4. Mungroop TH, van Rijssen LB, van Klaveren D, et al. Alternative Fistula Risk Score for Pancreatoduodenectomy (a-FRS): Design and International External Validation. Ann Surg 2019;269:937-43.

5. Li Y, Zhou F, Zhu DM, et al. Novel risk scoring system for prediction of pancreatic fistula after pancreaticoduodenectomy. World J Gastroenterol 2019;25:2650-64.

6. Yamamoto Y, Sakamoto Y, Nara S, et al. A preoperative predictive scoring system for postoperative pancreatic

Cite this article as: Eskander MF, Cloyd JM. Predicting post-operative pancreatic fistula: one size may not fit all. HepatoBiliary Surg Nutr 2021;10(1):113-115. doi: 10.21037/ hbsn-20-497 fistula after pancreaticoduodenectomy. World J Surg 2011;35:2747-55.

7. Roberts KJ, Hodson J, Mehrzad H, et al. A preoperative predictive score of pancreatic fistula following pancreatoduodenectomy. HPB (Oxford) 2014;16:620-8.

8. Kantor O, Talamonti MS, Pitt HA, et al. Using the NSQIP Pancreatic Demonstration Project to Derive a Modified Fistula Risk Score for Preoperative Risk Stratification in Patients Undergoing Pancreaticoduodenectomy. J Am Coll Surg 2017;224:816-25.

9. Kang JS, Park T, Han Y, et al. Clinical validation of scoring systems of postoperative pancreatic fistula after pancreatoduodenectomy: applicability to Eastern cohorts? Hepatobiliary Surg Nutr 2019;8:211-8.

10. Nahm CB, Connor SJ, Samra JS, et al. Postoperative pancreatic fistula: a review of traditional and emerging concepts. Clin Exp Gastroenterol 2018;11:105-18.

11. Denbo JW, Bruno ML, Cloyd JM, et al. Preoperative Chemoradiation for Pancreatic Adenocarcinoma Does Not Increase 90-Day Postoperative Morbidity or Mortality. J Gastrointest Surg 2016;20:1975-85.

12. Ecker BL, McMillan MT, Allegrini V, et al. Risk Factors and Mitigation Strategies for Pancreatic Fistula After Distal Pancreatectomy: Analysis of 2026 Resections From the International, Multi-institutional Distal Pancreatectomy Study Group. Ann Surg 2019;269:143-9.

13. Pessaux P, Sauvanet A, Mariette C, et al. External pancreatic duct stent decreases pancreatic fistula rate after pancreaticoduodenectomy: prospective multicenter randomized trial. Ann Surg 2011;253:879-85.

14. Xourafas D, Ejaz A, Tsung A, et al. Population-Based Assessment of Selective Drain Placement During Pancreatoduodenectomy Using the Modified Fistula Risk Score. J Am Coll Surg 2019;228:583-91.

15. Xourafas D, Ejaz A, Tsung A, et al. Validation of early drain removal after pancreatoduodenectomy based on modified fistula risk score stratification: a population-based assessment. HPB (Oxford) 2019;21:1303-11. 